\title{
Attenuation of pressure-induced myogenic contraction and tyrosine phosphorylation by fasudil, a cerebral vasodilator, in rat cerebral artery
}

\author{
${ }^{1}$ Naohiro Masumoto, ${ }^{1}$ Yoshiyuki Tanabe, ${ }^{1}$ Maki Saito \& ${ }^{*, 1}$ Koichi Nakayama \\ ${ }^{1}$ Department of Pharmacology, Faculty of Pharmaceutical Sciences, University of Shizuoka, 52-1 Yada, Shizuoka City, Shizuoka \\ 422-8526, Japan
}

1 The mechanism by which fasudil inhibits pressure-induced myogenic contraction was studied with regard to tyrosine phosphorylation in rat cerebral artery. Intracellular $\mathrm{Ca}^{2+}$ concentration $\left(\left[\mathrm{Ca}^{2+}\right]_{\mathrm{i}}\right)$ and vessel diameter were simultaneously measured. Total tyrosine phosphorylation level and phosphorylation of tyrosine 419 on $p p 60^{\text {src }}$ required for its full catalytic activity were immunocytochemically detected in situ.

2 Fasudil $(1-100 \mu \mathrm{M})$ partially suppressed the increase in $\left[\mathrm{Ca}^{2+}\right]_{\mathrm{i}}$, and totally attenuated contraction elicited by pressurization from 10 to $60 \mathrm{mmHg}$. Furthermore, fasudil $(100 \mu \mathrm{M})$ significantly attenuated tyrosine phosphorylation and the activity of pp60 $0^{\text {src }}$ augmented in situ by pressure.

3 Herbimycin A $(1-100 \mathrm{nM})$ and genistein $(3-30 \mu \mathrm{M})$, tyrosine kinase inhibitors, effectively attenuated the pressure-induced increase in $\left[\mathrm{Ca}^{2+}\right]_{i}$, contraction, tyrosine phosphorylation, and activation of $p p 60^{s r c}$. Both fasudil and herbimycin A directly inhibited the pp60 $0^{s r c}$ activity in a cell free system.

4 Orthovanadate $(100 \mu \mathrm{M})$, a tyrosine phosphatase inhibitor, significantly potentiated the pressureinduced increase in $\left[\mathrm{Ca}^{2+}\right]_{\mathrm{i}}$ and contraction.

5 Nicardipine $(100 \mathrm{nM})$, a $\mathrm{Ca}^{2+}$ antagonist, completely inhibited pressure-induced increase in $\left[\mathrm{Ca}^{2+}\right]_{\mathrm{i}}$ and contraction, but affected neither tyrosine phosphorylation nor activity of $\mathrm{pp} 60^{s r c}$ in the pressurized arteries.

6 Arginine-glycine-aspartic acid-serine peptide $(1-100 \mu \mathrm{M})$ concentration-dependently reduced the pressure-induced contraction.

7 In addition to the hitherto reported vasodilatory actions of fasudil, the present results suggest the inhibition by fasudil of pressure-induced tyrosine phosphorylation and pp60 ${ }^{\text {src }}$ activation. The wide spectrum of inhibitory actions of fasudil may contribute to the effective attenuation of the pressureinduced contraction in the cerebral artery.

British Journal of Pharmacology (2000) 130, 219-230

Keywords: Rat cerebral artery; myogenic contraction; intracellular $\mathrm{Ca}^{2+}$ signalling; immunocytochemistry; tyrosine phosphorylation; pp60 $0^{s c c}$ activity; fasudil; nicardipine; herbimycin A

Abbreviations: DMSO, dimethyl sulphoxide; EDRF, endothelium-derived relaxing factor; EGTA, ethylene glycol-bis $(\beta$ aminoethylether) $\mathrm{N}, \mathrm{N}, \mathrm{N}^{\prime}, \mathrm{N}^{\prime}$-tetra-acetic acid; FAK, focal adhesion kinase; FITC, fluorescein isothiocyanate; $\mathrm{IgG}$, immunoglobulin $\mathrm{G}$; indo-1/AM, indol acetoxymethyl ester; $\left[\mathrm{Ca}^{2+}\right]_{\mathrm{i}}$, intracellular $\mathrm{Ca}^{2+}$ concentration; LNNA, $N^{\omega}$-nitro-L-arginine; MLC, myosin light chain; NO, nitric oxide; PBS, phosphate-buffered saline; PE, phycoerythrin; PSS, physiological salt solution; $\mathrm{R}_{405 / 485}$, ratio of fluorescence intensity; $\mathrm{SAH}$, subarachnoidal haemorrhage

\section{Introduction}

Fasudil [1-(5-isoquinolinesulphonyl)-homopiperazine: HA10 77], a new type of cerebral vasodilator, is different from currently used so-called $\mathrm{Ca}^{2+}$ antagonists/channel blockers, such as verapamil, nifedipine, and diltiazem, in that the drug possesses not only blocking action against $\mathrm{Ca}^{2+}$ entry (Asano et al., 1987; Takizawa et al., 1993) but also inhibitory effects on a variety of serine/threonine protein kinases, including myosin light chain kinase (Asano et al., 1989; Katsumata et al., 1997; Seto et al., 1991; 1995; Uchata et al., 1997), protein kinase C (Asano et al., 1989; Uehata et al., 1997), and Rho-associated kinase (Uehata et al., 1997). Furthermore, fasudil reversed experimental chronic cerebral vasospasm induced in a twohaemorrhage canine model (Asano et al., 1987; Takayasu et

*Author for correspondence;

E-mail: nakayamk@ys7.u-shizuoka-ken.ac.jp al., 1986) and effectively inhibited proliferation of bovine vascular smooth muscle cells in culture (Shirotani et al., 1991). Fasudil has been reported to be effective in patients with subarachnoidal haemorrhage (SAH), and was first permitted to be used in 1995 in Japan as a remedy for ischemic insults due to chronic cerebral vasospasm.

We previously reported that cerebral arteries isolated from various animal species including rats were particularly sensitive to a variety type of mechanical stimuli, such as increasing intraluminal pressure (Masumoto et al., 1997) and quick stretch (Nakayama, 1982; Nakayama et al., 1989; Nakayama \& Tanaka, 1988), and that these stimuli produced a contraction that was myogenic in nature. Furthermore, we reported that herbimycin A, a src-family tyrosine kinase inhibitor, specifically attenuated the pressure-induced myogenic contraction of the rat cerebral artery (Masumoto et al., 1997). 
It was previously reported by us that a small amount of erythrocyte lysate (haemolysate) containing $0.01-0.2 \mathrm{mg} \mathrm{ml}^{-1}$ as oxyhaemoglobin potentiated the stretch-induced contraction of the canine basilar artery and that the enhancement was suppressed by $\mathrm{Ca}^{2+}$ antagonists (Nakayama et al., 1989). The components of erythrocyte lysate, such as oxyhemoglobin and other molecules, have been considered to be causal agents in the genesis of cerebral vasospasm after SAH. More recently, it was reported that haemolysate-induced cerebral vasocontraction was effectively attenuated by genistein, a tyrosine kinase inhibitor (Kim et al., 1998). Furthermore, tyrosine phosphorylations were induced by haemolysate in endothelial cells of bovine cerebral artery (Marton et al., 1996) and in smooth muscle cells of rat cerebral artery (Iwabuchi et al., 1999). As tyrosine phosphorylation has been considered to be involved in the transduction of mechanical forces in vascular reactions, including contraction and remodelling under pathological conditions such as hypertension, arteriosclerosis, and restenosis after angioplasty (Lehoux \& Tedgui, 1998), a drug to control tyrosine phosphorylation seems to be a good alternative to prevent vasospastic episodes and hypertrophic events in the vasculature.

The present experiments were thus undertaken to clarify how fasudil affects the myogenic contractile reactivity, the intracellular $\mathrm{Ca}^{2+}$ concentration $\left.\left(\left[\mathrm{Ca}^{2+}\right]_{\mathrm{i}}\right]\right)$, tyrosine phosphorylation, and pp60 $0^{s c c}$ activity assessed by phosphorylation of tyrosine 419 on the kinase required for its full catalytic activity (Piwnica-Worms et al., 1987), in the rat cerebral artery in response to a mechanical stimulus such as pressure. In addition, a direct effect of fasudil on pp $60^{s r c}$ activity was also investigated in a cell free system. Our present results suggest that fasudil effectively inhibits the pressure-induced tyrosine phosphorylation and $\mathrm{pp} 60^{\mathrm{src}}$ activation of rat cerebral artery, which may in part contribute to the inhibition of the contractile response to mechanical stimuli.

\section{Methods}

\section{Preparation of blood vessels}

Rat cerebral arteries were prepared according to the procedures reported previously (Masumoto et al., 1997). Briefly, male Sprague-Dawley rats, 9-13 weeks old and weighing 300-400 g (SLC, Hamamatsu, Japan), were anaesthetized with ether, and killed by decapitation. The secondary branch of the posterior cerebral artery (outer diameter of $142.8 \pm 13.1 \mu \mathrm{m}$ at intraluminal pressure of $10 \mathrm{mmHg}, n=243$ ) was carefully dissected from each hemisphere under a dissection microscope, and mounted on an experimental chamber of an arteriograph (A-2. Living Systems Instrumentation, Burlington, VT, U.S.A.), which was filled with HEPESbuffered physiological salt solution (PSS) of the following composition (in $\mathrm{mM}$ ): $\mathrm{NaCl} 158.3 ; \mathrm{KCl} 4.0 ; \mathrm{CaCl}_{2} 2.0 ; \mathrm{MgCl}_{2}$ 1.05; HEPES 10.42; glucose 5.6 High $\mathrm{KCl}$ (40 or $80 \mathrm{mM}$ ) PSS was prepared by replacing the $\mathrm{NaCl}$ with equimolar $\mathrm{KCl}$. The PSS was bubbled with $100 \%$ oxygen, and the $\mathrm{pH}$ was adjusted to 7.40 at $37^{\circ} \mathrm{C}$ with $1 \mathrm{~N} \mathrm{NaOH}$.

The intravascular pressure was controlled with a pressureservo system (PS-5, Living Systems Instrumentation, Burlington, VT, U.S.A.). The PSS in the vessel chamber was kept at $37 \pm 0.1^{\circ} \mathrm{C}$. In order to exclude effects of the endothelial cell layer, in the experiments on simultaneous measurement of $\left[\mathrm{Ca}^{2+}\right]_{\mathrm{i}}$ and arterial diameter, and in those on immnocytochemical in situ detections of phosphorylated tyrosine residues and pp60 ${ }^{s r c}$ activity, a heat-polished microcannula was passed back and forth through the lumen several times. Observation of light and scanning electron photomicrographs of the cerebral artery prepared repeatedly as described previously (Nakayama, 1988), indicated the absence of the endothelium. Unless otherwise stated in the text, to exclude effects of nitric oxide (NO) and cyclo-oxygenase products mainly derived from endothelial cell layer, $N^{\omega}$-nitro-L-arginine (L-NNA, $100 \mu \mathrm{M}$ ), an endothelium-derived relaxing factor (EDRF)/NO synthetase inhibitor (Ishii et al., 1990), and indomethacin (10 $\mu \mathrm{M})$, a cyclo-oxygenase inhibitor, were added to the chamber prior to the start of actual experiments.

\section{Measurement of $\left[\mathrm{Ca}^{2+}\right]_{i}$ and arterial diameter}

The arterial segment was equilibrated for $1 \mathrm{~h}$ at a steady pressure of $50 \mathrm{mmHg}$. After equilibration, the intraluminal pressure was raised from 0 to $120 \mathrm{mmHg}$ in stepwise increments of $30 \mathrm{mmHg}$ and lowered in a similar way to attenuate mechanical hysteresis (Masumoto et al., 1997). These manoeuvres were conducted three times at a 5-min interval. At the end of the third cycle, the artery was left at a pressure of $10 \mathrm{mmHg}$, under which condition no apparent pressureinduced contraction was observed (Masumoto et al., 1997), and then subjected to a series of subsequent pressure steps.

When we examined the effects of drugs, including fasudil, nicardipine, and arginine-glycine-aspartic acid-serine (RGDS) on the pressure-induced contraction, the following protocols were used. The intraluminal pressure was increased from 10 to $60 \mathrm{mmHg}$, and the change in diameter of the artery segment was observed for $5 \mathrm{~min}$. The pressure-induced contraction usually reached a maximum within $5 \mathrm{~min}$. Afterwards, the intraluminal pressure was returned to $10 \mathrm{mmHg}$. The pressurization was cycled at 10 -min intervals three times to secure a stable pressure-induced contraction, and the third response was taken as the control. The pressure-induced contractions were reproducible at least 15 times during an observation period of over $2 \mathrm{~h}$ (Masumoto et al., 1997). Each drug was added cumulatively between successive pressurestimuli. The pressurization was repeated until the maximal drug effect was obtained. When two successive responses were stable after application of the inhibitor, the second response was taken as the maximal response to the drug.

In a separate series of experiments, the $\left[\mathrm{Ca}^{2+}\right]_{\mathrm{i}}$ and arterial diameter were simultaneously measured according to the procedures used in previous studies (D'Angelo et al., 1997a, b; Himpens et al., 1992; Meininger et al., 1991). Briefly, arteries were loaded with indo-1, a fluorescent $\mathrm{Ca}^{2+}$-indicator, by a 1-h incubation at room temperature $\left(25^{\circ} \mathrm{C}\right)$ in PSS containing acetoxymethyl ester of indo-1 (indo-1/AM, $20 \mu \mathrm{M}$, dissolved in dimethyl sulphoxide as a stock solution of $1 \mathrm{~mm}$ ) and $0.025 \%$ cremophor $\mathrm{EL}^{\mathrm{R}}$, a nontoxic detergent. After the loading, the vessel segment was washed with $\mathrm{PSS}$ at $37^{\circ} \mathrm{C}$ to remove uncleaved indo-1/AM. The arteriograph was placed on the ACAS Ultima 575 UVC System interactive with a confocal laser microscope (Meridian, Okemos, MI, U.S.A.). Dual monitors simultaneously provided fluorescence and videoimage displays. This allowed us to compare the light optical and fluorescence images. The artery was illuminated by the excitation light of $357 \pm 6 \mathrm{~nm}$, and the indo-1 fluorescence was recorded at $405 \pm 5$ and $485 \pm 5 \mathrm{~nm}$ wavelengths. In our experiments, the laser scan strength was set at $25 \%$ of 33 $\mathrm{mW}$ output of a tunable 5-W Ar ultraviolet-visible laser (1-90, Coherent, U.S.A.), and a 7.5\% neutral density filter was used. The pinhole was set at $800 \mu \mathrm{m}$. Image scans $(\times 10$ objective, Zewiss, NA 0.3$)$ of $400 \times 400 \mu \mathrm{m}(1-\mu \mathrm{m}$ step size between respective XY points) were performed every $29 \mathrm{~s}$. When 
estimated $\left[\mathrm{Ca}^{2+}\right]_{\mathrm{i}}$ levels were to be reported, $\mathrm{Ca}^{2+}$-EGTA buffer mixtures were used to yield ionized $\left[\mathrm{Ca}^{2+}\right]$ between 50 and $1000 \mathrm{nM}$ measured with $40 \mu \mathrm{M}$ indo- 1 free acid at $\mathrm{pH}$ 7.4. The $\left[\mathrm{Ca}^{2+}\right]_{\mathrm{i}}$ was calculated by computer from a standard curve of the fluorescence ratio vs free $\mathrm{Ca}^{2+}$ in the $\mathrm{Ca}^{2+}$-EGTAHEPES buffer (Himpens et al., 1992). However, these values should be taken with caution, since the calculated $\left[\mathrm{Ca}^{2+}\right]_{i}$ values are only an estimate that depends on the calibration conditions used. Therefore, we expressed $\left[\mathrm{Ca}^{2+}\right]_{\mathrm{i}}$ in the figures as ratio units $\left(\mathrm{R}_{405 / 485}\right)$ unless otherwise stated in the text.

When the effect of each drug on the $\left[\mathrm{Ca}^{2+}\right]_{\mathrm{i}}$ and mechanical activity in response to pressure was tested, the following protocols were used: Each measurement was conducted at 1min intervals. Each drug was added after the diameter had become stable. The maximal drug effect was ordinarily obtained within $15 \mathrm{~min}$.

In the case of the assessment of each drug action on the contraction produced by either depolarizing or agonistic stimuli, the intraluminal pressure was kept at $10 \mathrm{mmHg}$ so as not to develop the pressure-induced myogenic contraction (Masumoto et al., 1997). The cerebral artery was contracted with $80 \mathrm{mM} \mathrm{KCl} \mathrm{PSS} \mathrm{or} \mathrm{by} 100 \mathrm{nM}$ 9,11-dideoxy-11 $\alpha, 9 \alpha$ epoxymethano prostaglandin $\mathrm{F}_{2 \alpha}$ (U46619), a stable analogue of thromboxane $\mathrm{A}_{2}$, at the concentration that produced a large and stable contraction over $2 \mathrm{~h}$.

At the end of each experiment, papaverine $(100 \mu \mathrm{M})$ was administered to totally climinate the contractions produced by the three different kinds of stimuli (Masumoto et al., 1997). For quantitative assessment of the drug action, the diameter of the artery segment was measured before and after administration of the drug, and was subtracted from that in the presence of papaverine. The arterial diameter in the presence of papaverine was taken as $100 \%$.

\section{Immunocytochemical in situ detections of phosphorylated tyrosine residues and pp $60^{\mathrm{src}}$ activity}

Immnocytochemical in situ detections of total phosphorylated tyrosine residues (Muller et al., 1996; 1997), and pp60 ${ }^{s r c}$ activity assessed by phosphorylation of tyrosine 419 on the kinase required for its full catalytic activity (Piwnica-Worms et al., 1987), were carried out. Briefly, rat cerebral arteries were isolated, mounted on the arteriograph, and kept from developing myogenic tone by maintaining a constant intraluminal pressure of $10 \mathrm{mmHg}$. The arteries were then pressurized from 10 to $60 \mathrm{mmHg}$ in the absence or the presence of each drug such as fasudil $(100 \mu \mathrm{M})$. For each experimental condition (pressurization alone or pressurization in the presence of each drug), basal tyrosine phosphorylation was determined in the control cerebral artery from the same brain, which was cannulated and not allowed to develop myogenic tone over the same time course. At the end of this protocol, $100 \mu \mathrm{M}$ sodium orthovanadate, a tyrosine phosphatase inhibitor, was added. After removal of the arteries from the cannulating pipettes, the arteries were fixed with $2 \%$ paraformaldehyde in phosphate-buffered saline (PBS). The fixation was followed by two washes with PBS containing $0.1 \mathrm{~mm}$ glycine and a rinse with PBS. The vessels were then permeablilized with $0.1 \%$ Triton $\mathrm{X}-100$ in PBS, rinsed three times with PBS, and incubated with $1 \mu \mathrm{g} \mathrm{ml}^{-1}$ monoclonal anti- $\alpha$-smooth muscle actin antibody (diluted in PBS containing $0.9 \%$ sodium citrate, $2 \%$ horse serum, $1 \%$ albumin, $0.05 \%$ Triton X-100, and $0.025 \% \mathrm{NaN}_{3}$ ) for $45 \mathrm{~min}$. The antibody solution was removed by three washes with PBS containing $0.9 \%$ sodium citrate and $0.05 \%$ Triton X-100. The arteries were next incubated with $1 \mu \mathrm{g} \mathrm{ml}^{-1}$ phycoerythrin (PE)- conjugated monoclonal anti-mouse immunoglobulin $\mathrm{G}$ ( $\mathrm{IgG}$ ) antibody for $45 \mathrm{~min}$. This antibody solution was removed by three washes with PBS containing $0.9 \%$ sodium citrate and $0.05 \%$ Triton $\mathrm{X}-100$. The vessels were finally incubated with $1 \mu \mathrm{g} \mathrm{ml}^{-1}$ fluorescein isothiocyanate (FITC)-conjugated monoclonal anti-phosphotyrosine antibody for $45 \mathrm{~min}$, with subsequent antibody removal by three washes with PBS containing $0.9 \%$ sodium citrate and $0.05 \%$ Triton X-100.

In a separate series of experiments, immunocytochemical in situ detection of $\mathrm{pp} 60^{\mathrm{sr}}$ activity was carried out with an antibody against a chemically synthesized phosphopeptide derived from the region of $\mathrm{pp} 60^{s r c}$ that contains the tyrosine residue positively regulating its activity (rabbit anti-src $\left[\mathrm{pY}^{418}\right]$ phosphospecific antibody, $1 \mu \mathrm{g} \mathrm{ml}^{-1}$, BioSource International, Camarillo, CA, U.S.A.) for the primary antibody and FITCconjugated goat anti-rabbit $\operatorname{IgG}\left(1 \mu \mathrm{g} \mathrm{ml}^{-1}\right)$ for the secondary antibody.

In order to perform the immunocytochemical in situ detections, the arteries were then transferred to a culture dish that was thereafter placed on the ACAS Ultima 575 UVC System. In the present experiments, the laser scan strength was set at $50 \%$ of $33-\mathrm{mW}$ output, and a $7.5 \%$ neutral density filter was used. The pinhole was set at $800 \mu \mathrm{m}$. Image scans $(\times 40$ water objective, Zewiss, NA 1.2) of $200 \times 200 \mu \mathrm{m}(0.5-\mu \mathrm{m}$ step size between respective $X Y$ points) were performed every $61 \mathrm{~s}$. A clear focus of the smooth muscle cells of each vessel was obtained under bright-field illumination. Four or five fluorescent images from each vessel were acquired using an excitation wavelength of $480 \pm 5 \mathrm{~nm}$ and an emission wavelength of $580 \pm 5 \mathrm{~nm}$ for PE and $530 \pm 5 \mathrm{~nm}$ for FITC with photomultipliers (R2949, Hamamatsu Photonics, Hamamatsu, Japan). Background fluorescence was subtracted, and the resultant images were captured and stored on a computer within the system.

\section{Measurement of pp60 $0^{\mathrm{src}}$ activity in cell free system}

Effects of fasudil and herbimycin A on pp60 src activity were investigated by use of protein tyrosine kinase assay kit (QIA28, Calbiochem, San Diego, CA, U.S.A.), based on the previous report (Schraag et al., 1993). Briefly, pp60 ${ }^{s r c}$ (4U) and either fasudil $(1-100 \mu \mathrm{M})$ or herbimycin $\mathrm{A}(1-100 \mathrm{nM})$ were added to each well of a 96-well microtiter plate which was precoated with a random polymer substrate containing multiple tyrosine residues. The kinase reaction was started by addition of kinase reaction buffer $(90 \mu \mathrm{l})$ including $0.1 \mathrm{mM}$ ATP to each well, and the plate was incubated at room temperature for $30 \mathrm{~min}$. The wells were washed six times with wash buffer making sure each well was filled completely. The horseradish peroxidase conjugated PY20, an anti-phosphotyrosine antibody, diluted with kinase reaction buffer (without ATP) was added to each well, and the plate was incubated at room temperature for $30 \mathrm{~min}$. The substrate solution including tetra-methylbenzidine, a chromogenic substrate, was added to each well, and the plate was incubated in the dark at room temperature for 6 min. The stop solution containing $2.5 \mathrm{~N} \mathrm{H}_{2} \mathrm{SO}_{4}$ was added to each well. The absorbance in each well was measured by use of a spectrophotometric plate reader (MTP-32, Corona Electric, Tokyo, Japan) at a wavelength of $450 \mathrm{~nm}$. Each value represents the mean \pm s.e.mean of five determinations.

\section{Chemicals}

The following drugs were used: Fasudil hydrochloride was donated by Asahi Chemical Industry (Tokyo, Japan). Herbimycin A, genistein, daidzein, sodium orthovanadate, 
nicardipine hydrochloride, indomethacin, papaverine hydrochloride, EGTA (ethylene glycolbis $(\beta$-aminoethylether) $\mathrm{N}, \mathrm{N}, \mathrm{N}^{\prime}, \mathrm{N}^{\prime}$-tetra-acetic acid), cremophor $\mathrm{EL}^{\mathrm{R}}$, PEconjugated monoclonal anti-mouse IgG antibody, and monoclonal anti- $\alpha$-smooth muscle actin antibody were purchased from Sigma (St. Louis, MO, U.S.A.). 9,11Dideoxy-11 $\alpha, 9 \alpha$-epoxymethano prostaglandin $\mathrm{F}_{2 \alpha}$ (U46619) was obtained from Cayman (Ann Arbor, MI, U.S.A.); $N^{\omega}$ nitro-L-arginine (L-NNA), from Aldrich Chemical Company (Milwaukee, WI, U.S.A.); acetoxymethyl ester of indo-1 (indo1/AM), from Dojindo Laboratories (Kumamoto, Japan); FITC-conjugated monoclonal anti-phosphotyrosine antibody, from Up State Biochemistry (New York, NY, U.S.A.); arginine-glycine-aspartic acid-serine (RGDS), from Peptide Institute, Inc. (Osaka, Japan); protein tyrosine kinase assay kit (QIA28), from Calbiochem (San Diego, CA, U.S.A.); rabbit anti-src $\left[\mathrm{pY}^{418}\right]$ phosphospecific antibody, from BioSource International (Camarillo, CA, U.S.A.); and FITC-conjugated goat anti-rabbit $\operatorname{lgG}$, from Molecular Probes (Eugene, OR, U.S.A.). Other drugs used were of reagent quality. U46619 was dissolved in ethanol at $100 \mu \mathrm{M}$. Indomethacin was dissolved in $0.1 \mathrm{M} \mathrm{NaHCO}_{3}$ solution at $10 \mathrm{~mm}$. Herbimycin A, genistein, and daidzein were dissolved in dimethyl sulphoxide (DMSO). The final concentrations of DMSO and ethanol did not exceed $0.1 \%$ in the organ bath. In a preliminary study, this concentration $(0.1 \%)$ of DMSO or ethanol had no significant effect on the pressure-induced contraction, and did not result in any detectable change in the $\left[\mathrm{Ca}^{2+}\right]_{\mathrm{i}}$ or mechanical activity. Fasudil hydrochloride, nicardipine hydrochloride, sodium orthovanadate, L-NNA, and papaverine hydrochloride were dissolved in distilled water. RGDS was solubilized in fresh PSS. All drugs were added to the chamber, and final concentrations were expressed as a molar concentration (M).

\section{Statistical analysis}

All data were expressed as mean \pm s.e.mean. The value of $\mathrm{EC}_{50}$ or $\mathrm{IC}_{50}$ was determined geometrically from logarithmic concentration-response curves. Student's $t$-test for paired data was used to determined the significance of differences between means. Tukey's test for multiple comparison was used after analysis of variance (ANOVA) to determine the significance of differences among means. A value of $P<0.05$ was considered significant.

\section{Results}

\section{Characteristic nature of $\left[\mathrm{Ca}^{2+}\right]_{i}$ and mechanical response to pressurization}

Figure 1 shows simultaneous recordings of $\left[\mathrm{Ca}^{2+}\right]_{i}$ and mechanical responses of rat cerebral artery when the intraluminal pressure was increased from 10 to $60 \mathrm{mmHg}$. The ratio of fluorescence intensity, $\mathrm{R}_{405 / 485}$, a measure of $\left[\mathrm{Ca}^{2+}\right]_{\mathrm{i}}$, at $10 \mathrm{mmHg}$ was $0.58 \pm 0.06$, arbitrarily corresponding to a $\left[\mathrm{Ca}^{2+}\right]_{\mathrm{i}}$ of $87.9 \pm 11.6 \mathrm{nM}(n=5)$. The intracellular $\mathrm{Ca}^{2+}$ signal was transiently increased with pressurization. Afterwards, it reached a stable level within $5 \mathrm{~min}$ and lasted for at least $90 \mathrm{~min}$. The vessel was passively inflated with an increase in intraluminal pressure from 10 to $60 \mathrm{mmHg}$, and was followed by a delayed contraction that reached a maximum within 5 min after application of the pressure. The contraction reached stable and lasted for at least $90 \mathrm{~min}$. The effective pressure producing $50 \%$ of maximal contraction was $40.7 \pm 4.0 \mathrm{mmHg}(n=5)$. In order to decrease $\left[\mathrm{Ca}^{2+}\right]_{\mathrm{i}}$ to resting level and to eliminate totally the vascular tone, the artery was treated with papaverine $(100 \mu \mathrm{M})$ (Masumoto et al., 1997; Tanaka et al., 1995). The arterial diameter in the presence of papaverine was taken as $100 \%$ on the ordinate of the figure. The relationship between $\left[\mathrm{Ca}^{2+}\right]_{\mathrm{i}}$ and the change in diameter in response to pressurization from 10 to 20,40 or $60 \mathrm{mmHg}$ was approximately parallel, as shown in Figure $1 \mathrm{~b}$.

In the next step, we compared the effect of depolarizing and agonistic stimuli on the cerebral artery. The artery relaxed slightly when $\mathrm{KCl}$ in the medium was increased from 4 to $20 \mathrm{~mm}$, and contraction occurred from over $20 \mathrm{~mm}$ up to $80 \mathrm{~mm}$ in a concentration-dependent manner. The contraction reached a maximum at $80 \mathrm{mM} \mathrm{KCl}$, and an $\mathrm{EC}_{50}$ value was $45.6 \pm 8.2 \mathrm{mM} \quad(n=12)$. A further increase in the $\mathrm{KCl}$ concentration $(100 \mathrm{mM})$ depressed the contraction of the artery. Therefore, in the subsequent study, we tested each drug on the contraction produced by $80 \mathrm{mM} \mathrm{KCl}$. A separate series of experiments indicated that $\mathrm{R}_{405 / 485}$, a measure of

a

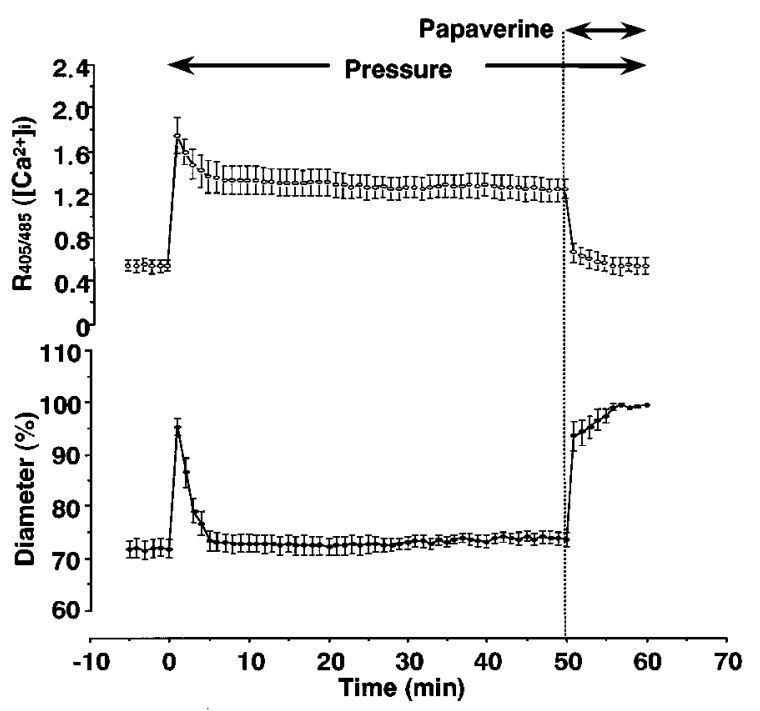

b

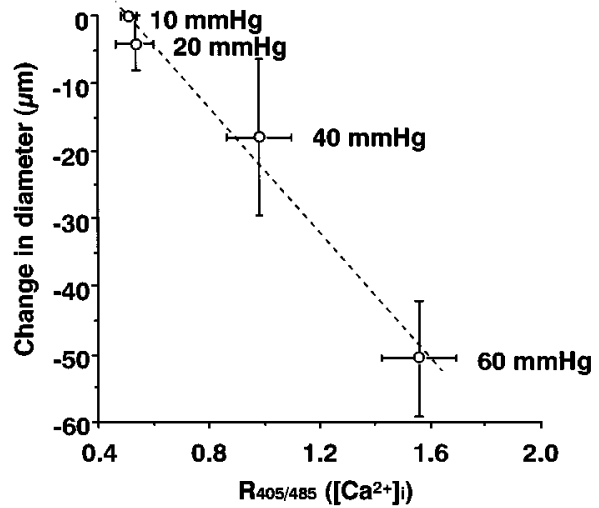

Figure 1 Pressure-induced increase in $\left[\mathrm{Ca}^{2+}\right]_{\mathrm{i}}$ and myogenic contraction of rat cerebral artery loaded with indo-1. (a) Time course of $\left[\mathrm{Ca}^{2+}\right]_{\mathrm{i}}$ and arterial diameter in response to a pressure stimulus from 10 to $60 \mathrm{mmHg}$. $\left[\mathrm{Ca}^{2+}\right]_{\mathrm{i}}$ (open circle; upper part of panel A) is expressed as the ratio of fluorescence intensity at 405 to that at $485 \mathrm{~nm}\left(\mathrm{R}_{405 / 485}\right)$ in the upper panel. Arterial diameter (closed circle; lower part of panel A) at $60 \mathrm{mmHg}$ in the presence of $100 \mu \mathrm{m}$ papaverine $(197.6 \pm 13.5 \mu \mathrm{m}, n=5)$ was taken as $100 \%$ in the lower panel, and that at $10 \mathrm{mmHg}$ was $143.5 \pm 12.0 \mu \mathrm{m}$ (per cent diameter $=72.4 \pm 1.7)$. The $\left[\mathrm{Ca}^{2+}\right]_{i}$ and contractile response lasted stable for at least 60 to $90 \mathrm{~min}$ (outer diameter $=146.8 \pm 10.8 \mu \mathrm{m}$, per cent diameter $=74.2 \pm 1.4$ ). (b) The relationship between $\left[\mathrm{Ca}^{2+}\right]_{\mathrm{i}}$ and the change in diameter $(\mu \mathrm{m})$ in response to pressurization from 10 to 20,40 or $60 \mathrm{mmHg}$. Each point represents the mean \pm s.e.mean of five preparations. 
$\left[\mathrm{Ca}^{2+}\right]_{\mathrm{i}}$, and the arterial diameter before the depolarizing stimulation were $0.50 \pm 0.01 \quad\left(\left[\mathrm{Ca}^{2+}\right]_{\mathrm{i}}=82.6 \pm 4.6 \mathrm{nM}\right)$ and $149.2 \pm 5.7 \mu \mathrm{m}$, respectively. With application of $80 \mathrm{mM} \mathrm{KCl}$, the rapid increase in $\left[\mathrm{Ca}^{2+}\right]_{\mathrm{i}}$ within $1-2$ min was followed by contraction of the artery; and then the $\left[\mathrm{Ca}^{2+}\right]_{\mathrm{i}}$ and the diameter reached a steady state level $\left(\mathrm{R}_{405 / 485}=1.51 \pm 0.05\right.$, $\left[\mathrm{Ca}^{2+}\right]_{\mathrm{i}}=342.6 \pm 13.6 \mathrm{nM}$; diameter $=101.0 \pm 6.4 \mu \mathrm{m}$, per cent diameter $=64.4 \pm 2.5$ based on $100 \mu \mathrm{M}$ papaverine $=100 \%$, each $n=5)$.

U46619 (1-100 nM) produced a concentration-dependent contraction of the rat cerebral artery with an $\mathrm{EC}_{50}$ value of $31.7 \pm 10.3 \mathrm{nM}(n=13)$. U46619 at $100 \mathrm{~nm}$ produced a large and long-lasting contraction, which was suitable for the evaluation of the vasodilator action of the inhibitors (Masumoto et al., 1997; Tanaka et al., 1995). $\mathrm{R}_{405 / 485}$ and the outer diameter before the U46619 stimulus were $0.46 \pm 0.05\left(\left[\mathrm{Ca}^{2+}\right]_{\mathrm{i}}=79.5 \pm 9.8 \mathrm{nM}\right)$ and $151.0 \pm 10.4 \mu \mathrm{m}$ (per cent diameter $=95.5 \pm 1.4$ based on $100 \mu \mathrm{M}$ papaverine $=100 \%)$, respectively. U46619 (100 nM) elicited at the steady-state level an increase in $\left[\mathrm{Ca}^{2+}\right]_{\mathrm{i}}\left(\mathrm{R}_{405 / 485}\right.$ $=0.98 \pm 0.14,\left[\mathrm{Ca}^{2+}\right]_{\mathrm{i}}=201.9 \pm 28.2 \mathrm{nM}$ ) and contraction (outer diameter $=105.2 \pm 5.1 \mu \mathrm{m}, 68.2 \pm 3.4 \%$, each $n=5$ ). In the case of the U46619-induced contraction, the steady-state level in $\left[\mathrm{Ca}^{2+}\right]_{\mathrm{i}}$ was relatively lower than that induced by either pressurization or depolarizing stimulus.

\section{Effect of fasudil on $\left[\mathrm{Ca}^{2+}\right]_{i}$ and mechanical responses to pressurization}

Figure 2 shows the comparative effects of fasudil and nicardipine on the increased $\left[\mathrm{Ca}^{2+}\right]_{i}$ and narrowed vessel diameter in response to pressure. Interestingly, the simultaneous recordings of $\left[\mathrm{Ca}^{2+}\right]_{i}$ and mechanical responses to the three different stimuli indicated that fasudil and nicardipine acted differentially on both parameters. Typical tracings showed that the cumulative application of fasudil decreased both $\left[\mathrm{Ca}^{2+}\right]_{i}$ and the contraction in a concentration-dependent manner (Figure 2a). At the highest concentrations used in the present study, fasudil $(100 \mu \mathrm{M})$ inhibited almost completely the myogenic contraction in spite of causing only a partial suppression of the increased $\left[\mathrm{Ca}^{2+}\right]_{\mathrm{i}}$, whereas nicardipine (100 nM) abolished both responses (Figure 2b). As summarized in Table 1, fasudil inhibited the concentrations produced by the three different kinds of stimulation in a similar manner with a $50 \%$ inhibitory concentration $\left(\mathrm{IC}_{50}\right)$ of $5-7 \mu \mathrm{M}$, and the maximal inhibition, over $90 \%$, occurred at $100 \mu \mathrm{M}$. Nicardipine mostly inhibited the contractile responses produced by pressurization or depolarizing stimulus, whereas the drug inhibited the U46619-induced contraction less than half (Table 1).

Fasudil $(100 \mu \mathrm{M})$ almost completely inhibited the mechanical events, but partially suppressed the increased values of $\mathrm{R}_{405 / 485}$, i.e., from $1.51 \pm 0.03$ to $1.08 \pm 0.08(P<0.05, n=5)$ for a pressure stimulus (see Figure 2a), from $1.63 \pm 0.10$ to $1.16 \pm 0.06(P<0.05, n=5)$ for $80 \mathrm{mM} \mathrm{KCl}$, and from $1.07 \pm 0.06$ to $0.83 \pm 0.05 \quad(P>0.05, n=5)$ for $\mathrm{U} 46619$. Nicardipine $(100 \mu \mathrm{M})$ reduced the increased values of $\mathrm{R}_{405 / 485}$ in response to all three different stimuli mostly to the resting level, i.e., from $1.47 \pm 0.04$ to $0.52 \pm 0.06(P<0.01, n=5)$ for pressure, $1.70 \pm 0.08$ to $0.62 \pm 0.06(P<0.01, n=5)$ for $80 \mathrm{mM}$ $\mathrm{KCl}$, and $0.92 \pm 0.08$ to $0.53 \pm 0.02 \quad(P<0.05, n=5)$ for U46619.

In order to clarify whether tyrosine kinase regulates intracellular $\mathrm{Ca}^{2+}$ signalling in the genesis of the pressureinduced contraction, we examined the effects of herbimycin $\mathrm{A}$ and genistein on the $\left[\mathrm{Ca}^{2+}\right]_{i}$ and mechanical activity. Herbimycin A (100 nM) significantly reduced the $\mathrm{R}_{405 / 485}$ that

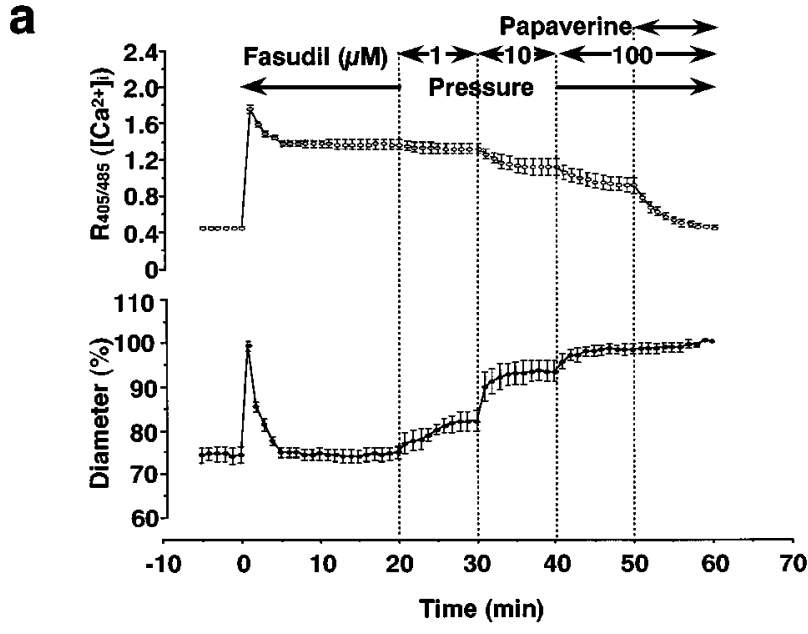

b



Figure 2 Effects of fasudil and nicardipine on the pressure-induced changes in $\left[\mathrm{Ca}^{2+}\right]_{i}$ and diameter of rat cerebral artery. (a) Simultaneous measurements of $\left[\mathrm{Ca}^{2+}\right]_{i}$ and diameter changed by a pressure stimulus from 10 to $60 \mathrm{mmHg}$ and the effect of fasudil. (b) Summarized data representing the concentration-response relation as to the effects of fasudil (open circle; upper part of panel a) and nicardipine (closed circle; lower part of panel a) on the $\left[\mathrm{Ca}^{2+}\right]_{i}$ and arterial diameter. Each point represents the mean \pm s.e. mean of four preparations. Corresponding control values in the absence of fasudil are not significantly different from those in the absence of nicardipine.

Table 1. Inhibitory effects of fasudil and nicardipine on contractions produced by three different types of stimuli

\begin{tabular}{llrcc}
\hline & & \multicolumn{3}{c}{ Stimulus } \\
Drugs & & Pressure & KCI $(80 \mathrm{nM})$ & U46619 \\
& & & & \\
Fasudil & $\mathrm{IC}_{50}(\mu \mathrm{M})$ & $4.8 \pm 0.8$ & $4.9 \pm 2.1$ & $6.9 \pm 1.8$ \\
& $\%$ Maximal & $99.3 \pm 0.5$ & $93.1 \pm 1.9$ & $95.6 \pm 1.7$ \\
& $\quad$ inhibition & & & \\
Nicardipine & $\mathrm{IC}_{50}(\mu \mathrm{M})$ & $2.3 \pm 0.9$ & $5.4 \pm 3.8$ & $>100$ \\
& $\%$ Maximal & $91.0 \pm 2.4$ & $90.0 \pm 3.7$ & $42.6 \pm 1.5$ \\
& inhibition & & &
\end{tabular}

Each value represents the mean + s.e.mean of five separate experiments.

was increased by pressure, and the resultant contraction was also almost totally suppressed by the drug (Figure 3a). Summarized data indicated that $\left[\mathrm{Ca}^{2+}\right]_{\mathrm{i}}$ and contraction in response to pressure were inhibited by herbimycin $\mathrm{A}$ in a concentration-dependent manner (Figure 3b). Herbimycin A $(100 \mathrm{nM})$ at the maximal concentration used reduced the maximal contraction in the pressure-contraction relationship, and the effective pressure producing $50 \%$ of maximal 
contraction was $42.9 \pm 7.3 \mathrm{mmHg}$ in the control and $46.8 \pm 6.9 \mathrm{mmHg}$ in the presence of $100 \mathrm{nM}$ herbimycin A (each $n=4, P>0.05$ vs control), respectively, indicating that the inhibition by herbimycin $\mathrm{A}$ of the pressure-induced contraction was noncompetitive. However, herbimycin A (100 nM) neither significantly changed the $80 \mathrm{mM} \mathrm{KCl-induced}$ increase in $\mathrm{R}_{405 / 485}(1.38 \pm 0.10$ to $1.39 \pm 0.08, P>0.05, n=5)$ nor altered the narrowed arterial diameter $(64.2 \pm 0.7$ to $65.8 \pm 1.6 \%$, based on $100 \mu \mathrm{M}$ papaverine $=100 \%, P>0.05)$. Herbimycin A (100 nM) slightly changed the U46619-induced increase in $\mathrm{R}_{405 / 485}(1.13 \pm 0.03$ to $1.07 \pm 0.03, P>0.05, n=5)$, and the resultant contraction $(61.5 \pm 4.1$ to $60.6 \pm 3.8 \%$, $P>0.05)$.

Genistein $(3-30 \mu \mathrm{M})$ concentration-dependently inhibited the increase in $\mathrm{R}_{405 / 485}$ induced by pressure and totally suppressed the resultant contraction in response to pressure (Figure $3 \mathrm{~b})$. Genistein $(30 \mu \mathrm{M})$ at the maximal concentration used reduced the maximal contraction in the pressurecontraction relationship, and the effective pressure producing $50 \%$ of maximal contraction was $43.3 \pm 5.8 \mathrm{mmHg}$ in the control and $45.6 \pm 7.3 \mathrm{mmHg}$ in the presence of $30 \mu \mathrm{M}$ genistein (each $n=4, P>0.05$ vs control), indicating that the

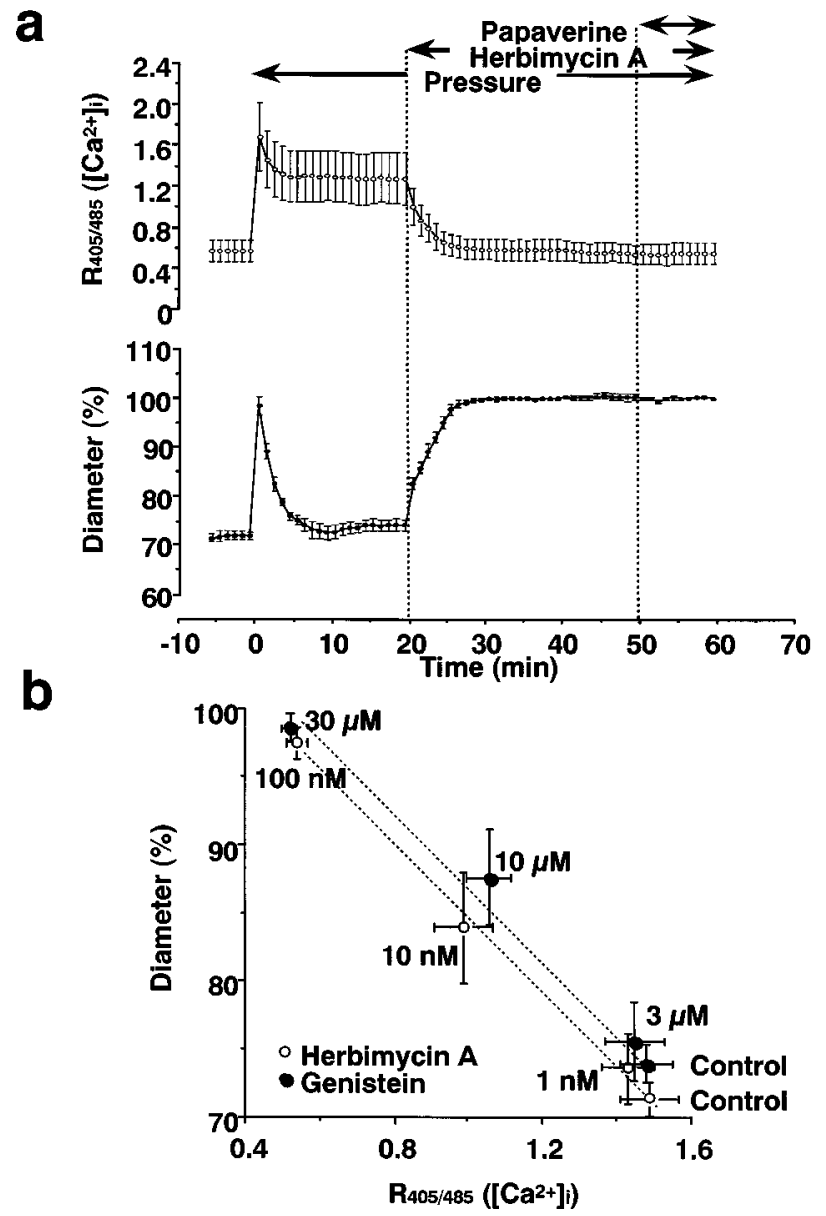

Figure 3 Effects of tyrosine kinase inhibitors on the $\left[\mathrm{Ca}^{2+}\right]_{\mathrm{i}}$ and arterial diameter of rat cerebral arteries in response to a pressure stimulus. (a) Herbimycin A $(100 \mathrm{~nm})$ significantly inhibited the $\left[\mathrm{Ca}^{2+}\right]_{\mathrm{i}}$ (open circle; upper part of panel a) and the resultant contraction (closed circle; lower part of panel a) increased by a pressure stimulus from 10 to $60 \mathrm{mmHg}$. (b) Summarized data representing the concentration-response relation as to the effects of herbimycin A (open circle) and genistein (closed circle) on the $\left[\mathrm{Ca}^{2+}\right]_{\mathrm{i}}$ and arterial diameter. Each point represents the mean \pm s.e. mean of four to five preparations. Corresponding control values in the absence of herbimycin A are not significantly different from those in the absence of genistein. inhibition by genistein of the pressure-induced contraction was also noncompetitive in nature. Genistein $(30 \mu \mathrm{M})$ did not significantly affect the $80 \mathrm{mM} \mathrm{KCl}$-induced increase in $\mathrm{R}_{405 / 485}$ $(1.32 \pm 0.11$ to $1.33 \pm 0.07, P>0.05, n=5)$ or contraction $(62.0 \pm 3.0$ to $61.8 \pm 2.0 \%$, based on $100 \mu \mathrm{M}$ papaverine $=100 \%, P>0.05)$. In contrast to herbimycin A, genistein $(30 \mu \mathrm{M})$ significantly attenuated the increased $\mathrm{R}_{405 / 485}$ elicited by U46619 (100 nM) $(1.14 \pm 0.10$ to $0.55 \pm 0.06, P<0.05$, $n=5)$, and abolished the resultant contraction $(64.4 \pm 3.4$ to $99.2 \pm 0.7 \%, P<0.01)$. Daidzein $(30 \mu \mathrm{M})$, a negative control drug for genistein, affected neither the $\mathrm{R}_{405 / 485}$ values nor the resultant contractions in response to pressure, high $\mathrm{KCl}$, or U46619 (data not shown).

Orthovanadate $(100 \mu \mathrm{M})$, a tyrosine phosphatase inhibitor, significantly potentiated the pressure-induced increase in $\mathrm{R}_{405 / 485} \quad(1.48 \pm 0.05$ to $1.78 \pm 0.06, \quad P<0.05, \quad n=4) \quad$ and contraction $(78.4 \pm 1.8$ to $59.9 \pm 3.5 \%$, based on $100 \mu \mathrm{M}$ papaverine $=100 \%, \quad P<0.05) . \quad$ However, orthovanadate $(100 \mu \mathrm{M})$ did not apparently affect the $40 \mathrm{mM} \mathrm{KCl}$-induced increase in $\mathrm{R}_{405 / 485}(1.00 \pm 0.04$ to $0.99 \pm 0.04, P>0.05, n=4)$ or contraction $(79.3 \pm 2.5$ to $79.7 \pm 2.4 \%, P>0.05)$. On the other hand, orthovanadate $(100 \mu \mathrm{M})$ significantly augmented the increased $\mathrm{R}_{405 / 485}$ elicited by U46619 (30 nM) $(0.83 \pm 0.07$ to $1.12 \pm 0.08, P<0.05, n=4)$, and potentiated the resultant contraction $(78.8 \pm 2.5$ to $61.1 \pm 3.5 \%, P<0.05)$.

In order to clarify whether integrin is involved in the genesis of pressure-induced contraction, we examined an effect of arginine-glycine-aspartic acid-serine (RGDS) on the contractile response. RDGS peptide $(1-100 \mu \mathrm{M})$ concentration-dependently reduced the pressure-induced myogenic contraction with an $\mathrm{IC}_{50}$ value of $12.6 \pm 4.5 \mu \mathrm{M}(n=4)$. The maximal inhibition of the pressure-induced contraction by RGDS $(100 \mu \mathrm{M})$ was $81.7 \pm 3.9 \%$, based on $100 \mu \mathrm{M}$ papaverine $=100 \%(n=4)$. The peptide $(1-100 \mu \mathrm{M})$ had no apparent effect on high KCl- or U46619-induced contractions (data not shown).

\section{Effect of fasudil on tyrosine phosphorylation}

Typical images of rat cerebral artery subjected to pressure before and after application of fasudil and stained immunofluorescently for phosphotyrosine and the summarized data are shown in Figures 4 and 5, respectively. The image of a vessel under the control condition (no pressurization) is also shown in Figure 4a. Fluorescence intensity (arbitrary units) with antiphosphotyrosine staining was significantly increased in vessels pressurized from 10 to $60 \mathrm{mmHg}$. The image of the artery stained by anti-phosphotyrosine antibody (Figure $4 \mathrm{~b}$ ) was identical to that of the one stained by anti- $\alpha$-smooth muscle actin antibody (Figure 4d), indicating that tyrosine phosphorylation occurred in medial smooth muscle cells of the same artery. Furthermore, the stained preparation showed that individual smooth muscle cells were oriented perpendicular to the longitudinal axis of the artery (Figure 4).

Pretreatments with fasudil $(100 \mu \mathrm{M})$, herbimycin A $(100 \mathrm{nM})$, and genistein $(30 \mu \mathrm{M})$, at which concentrations each drug totally inhibited the contraction in response to pressure, significantly reduced the pressure-induced increase in tyrosine phosphorylation (Figures $4 \mathrm{~b}, \mathrm{c}$ and $5 \mathrm{a}$, respectively), whereas nicardipine (100 $\mathrm{nM})$ and daidzein $(30 \mu \mathrm{M}$, data not shown) only slightly suppressed the pressure-induced tyrosine phosphorylation (Figure 5a).

A depolarizing stimulus such as high $\mathrm{KCl}(80 \mathrm{~mm})$ did not significantly affect the fluorescence intensity with antiphosphotyrosine staining in the artery $(10.0 \pm 4.2$ vs $22.8 \pm 9.6$, $P>0.05$, control arteries vs high $\mathrm{KCl}$-treated arteries, each $n=5)$. 

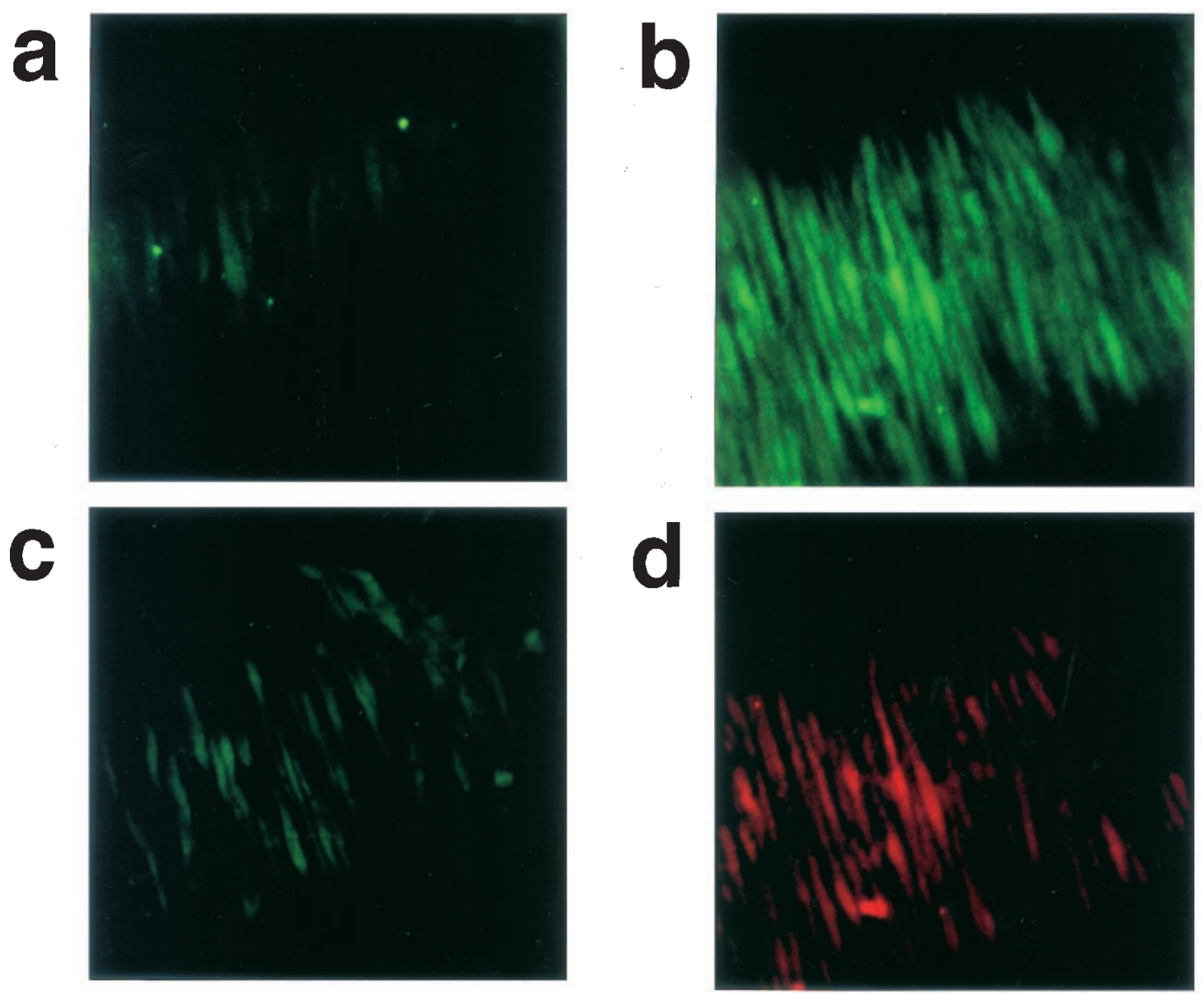

Figure 4 Effect of fasudil on pressure-induced tyrosine phosphorylation. Staining of phosphorylated tyrosine residues in rat cerebral arteries under control conditions (a) and following exposure to pressurization from 10 to $60 \mathrm{mmHg}$ for $5 \mathrm{~min}$ in the absence (b) or the presence of fasudil $(100 \mu \mathrm{M})(\mathrm{c})$. The image stained by anti-phosphotyrosine antibody (b) was identical to that stained by anti- $\alpha$-smooth muscle actin antibody (d), indicating that tyrosine phosphorylation occurred in the medial smooth muscle cells of the same artery.

U46619 (100 nM) significantly increased the fluorescence intensity in the artery (Figure 5b). Pretreatment with fasudil $(100 \mu \mathrm{M})$ significantly reduced the tyrosine phosphorylation (Figure 5b). It is noteworthy that herbimycin A and genistein acted differently on the tyrosine phosphorylation. Herbimycin A $(100 \mathrm{nM})$ did not significantly affect the tyrosine phosphorylation, whereas genistein $(30 \mu \mathrm{M})$ significantly attenuated the tyrosine phosphorylation (Figure 5b). Neither nicardipine (100 $\mathrm{nM})$ nor daidzein $(30 \mu \mathrm{M}$, data not shown) pretreatment, on the other hand, significantly inhibited the tyrosine phosphorylation (Figure 5b).

\section{Effect of fasudil on $p p 60^{\mathrm{src}}$ activity in situ}

The pp $60^{s r c}$ has two tyrosine residues that can be phosphorylated, and their phosphorylation states affect its kinase activity (Piwnica-Worms et al., 1987). The phosphorylation of tyrosine 419 positively regulates the kinase activity. Therefore, immunocytochemical in situ detection of the phosphorylated tyrosine 419 , a measure of the kinase activity, was carried out with an antibody against a chemically synthesized phosphopeptide derived from the region of $\mathrm{pp} 60^{s r c}$ that contains the tyrosine residue positively regulating its activity.

Typical images of rat cerebral arteries stained immunofluorescently for the phosphorylation indicating $\mathrm{pp} 60^{\text {src }}$ activity and the summarized data are shown in Figures 6 and 7 , respectively. Figure 6a shows the image of a vessel under the control condition (no pressurization). Fluorescence intensity (arbitrary units) was significantly increased in vessels pressurized from 10 to $60 \mathrm{mmHg}$ (Figure 6b). The image of the artery stained by anti-src $\left[\mathrm{pY}^{418}\right]$ phosphospecific antibody was identical to that of the one stained by anti- $\alpha$-smooth muscle actin antibody (data not shown), indicating that phosphorylation of the tyrosine residue on $\mathrm{pp}^{\circ} 0^{\mathrm{src}}$ occurred in medial smooth muscle cells of the same artery.

Pretreatments with fasudil $(100 \mu \mathrm{M})$, herbimycin A $(100 \mathrm{nM})$, and genistein $(30 \mu \mathrm{M})$ each for $20 \mathrm{~min}$ significantly reduced the pressure-induced increase in the phosphorylation of pp60 $0^{s r c}$ (Figures 6c,d and 7), whereas nicardipine (100 nM) and daidzein (30 $\mu \mathrm{M}$, data not shown) only slightly suppressed the phosphorylation (Figure 7).

\section{Effect of fasudil on $p p 60^{\mathrm{src}}$ activity in cell free system}

Fasudil significantly inhibited the pp60 $60^{s r c}$ activity in a concentration-dependent manner with an $\mathrm{IC}_{50}$ value of $32.5 \pm 2.3 \mu \mathrm{M}$ (Figure 8). Herbimycin A also significantly reduced the enzyme activity in a concentration-dependent manner with an $\mathrm{IC}_{50}$ value of $8.0 \pm 0.5 \mathrm{nM}$ (Figure 8).

\section{Discussion}

In the present study, we showed that fasudil $(1-100 \mu \mathrm{M})$ concentration-dependently inhibited the pressure-induced myogenic contraction of rat cerebral artery, and the drug at 


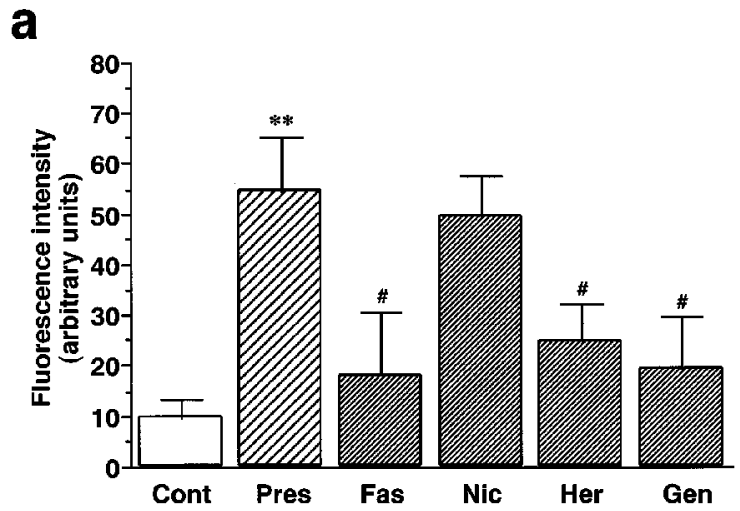

b

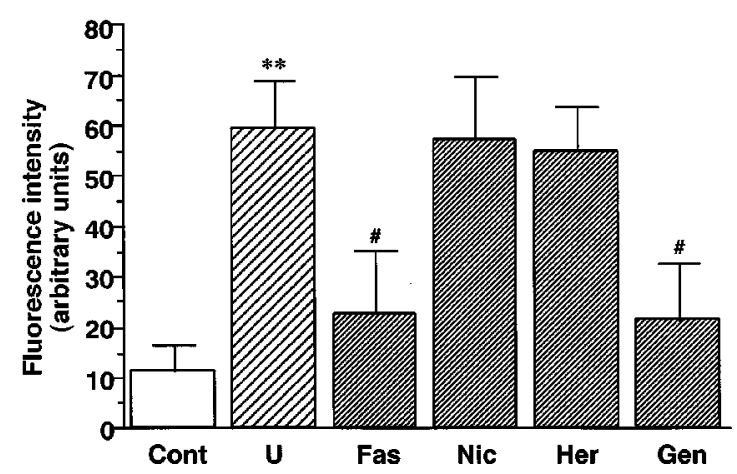

Figure 5 Effects of fasudil, nicardipine, herbimycin A, and genistein on tyrosine phosphorylation of rat cerebral artery. (a) Pressurization from 10 to $60 \mathrm{mmHg}$ significantly increased the fluorescence intensity. Note that fasudil (Fas) $(100 \mu \mathrm{M})$, herbimycin A (Her) $(100 \mathrm{nM})$, and genistein (Gen) $(30 \mu \mathrm{M})$ except nicardipine (Nic) $(100 \mathrm{nM})$ treatments significantly reduced the fluorescence intensity. (b) U46619 (100 nM) significantly potentiated fluorescence intensity. Note that fasudil $(100 \mu \mathrm{M})$ and genistein $(30 \mu \mathrm{M})$ except nicardipine $(100 \mathrm{nM})$ and herbimycin A $(100 \mathrm{nM})$ treatments significantly reduced the fluorescence intensity. Each column represents the mean + s.e. mean of five preparations. Cont, control; Pres, pressure; U, U46619. ** indicates $P<0.01$ vs corresponding control values. \# indicates $P<0.05$ vs corresponding values stimulated with either pressure (a) or U46619 (b).

$100 \mu \mathrm{M}$ abolished the mechanical activity in spite of its ability to only partially suppress the increase in $\left[\mathrm{Ca}^{2+}\right]_{\mathrm{i}}$ in response to intraluminal pressurization. The pressurization elicited a marked increase in total tyrosine phosphorylation level and pp60 ${ }^{s r c}$ activity assessed by phosphorylation of tyrosine 419 on the kinase required for its full catalytic activity (PiwnicaWorms et al., 1987), in medial smooth muscle cells of the artery. These augmentations were also inhibited by fasudil. In addition, the pp $60^{s r c}$ activity was directly inhibited by fasudil in a cell free system.

The contractile reaction of vascular tissue to mechanical stress is a kind of physical response and thus requires cellular signal transduction, which may be mediated through a receptive site specific for a mechanical stimulus and the pathways of $\mathrm{Ca}^{2+}$ signalling common to pharmacological agonists. It has been considered that vascular smooth muscle directly responds to mechanical forces in a variety of ways, including changes in membrane ionic conductance, activation/ inactivation of a number of second messenger systems, and changes in cytoskeletal structures (Osol, 1995). In the present study, the pressure-induced increase in $\left[\mathrm{Ca}^{2+}\right]_{i}$ and myogenic contraction of rat cerebral artery were abolished by nicardipine, a voltage-dependent L-type $\mathrm{Ca}^{2+}$ channel blocker.
Furthermore, the change in $\left[\mathrm{Ca}^{2+}\right]_{\mathrm{i}}$ and arterial diameter in response to varying pressure at the tonic contraction phase occurred in an almost parallel manner (see Figure 1b). Therefore, we consider that the activator $\mathrm{Ca}^{2+}$ involved in the pressure-induced contraction of the rat cerebral artery is mainly dependent on the transmembrane influx via voltagedependent L-type $\mathrm{Ca}^{2+}$ channels, and that any mechanism involved in $\mathrm{Ca}^{2+}$ sensitization plays a minor role in the pressure-induced contraction.

Integrins, a large family of heterodimeric transmembrane glycoproteins, have been considered to play an important role in the mechanotransduction in various tissues including vascular smooth muscle cells and endothelial cells (Ingber, 1991). With the binding of specific ligands or haemodynamic stimuli, including blood pressure and blood flow, integrins have been reported to activate a variety of biochemical signalling pathways. A feature common to many integrinbinding proteins is the presence of the tripeptide sequence, arginine-glycine-aspartic acid (RGD), (Ruoslahti \& Piersbacher, 1986; 1987). Mogford et al. (1996) reported that GlyPencillamine-Gly-Arg-Gly-Asp-Ser-Pro-Cys-Ala (cyclic RGD) or Gly-Arg-Gly-Asp-Ser-Pro (GRGDSP) counteracted the contraction of pressurized rat cremaster arterioles even after removal of the endothelium. Furthermore, the vasodilatory effect of the RGD peptides could be blocked almost completely by a function-blocking monoclonal antibody to $\beta_{3}$-integrin (F11) (Mogford et al., 1996). D'Angelo et al. (1997b) found that the RGD peptide decreased $\left[\mathrm{Ca}^{2+}\right]_{\mathrm{i}}$ and attenuated the contraction of pressurized rat cremaster arterioles. In the present study, we showed that RGDS peptide, Arg-Gly-AspSer, effectively suppressed the pressure-induced contraction of rat cerebral artery without any appreciable effects on the contractions in response to high $\mathrm{KCl}$ or U46619. Taken together with our results and those of others, it seems very likely that the interaction of integrins with extracellular matrix proteins is primarily involved in the genesis of pressureinduced myogenic contraction.

The interaction of integrins with ion channels has not been definitely established. There may be a direct coupling between the integrin and the channel protein, as suggested by Schwartz et al. (1993). They found a $50-\mathrm{kD}$ protein, termed integrinassociated protein, in endothelial cells, which has been considered to act as an ion channel or to directly interact with one. On the basis of such an arrangement, with mechanical stimuli and/or ligand, integrins could allosterically modulate channel function. Mechanogated membrane ion channels have been also considered to be another candidate as a mechanosensor (Osol, 1995). Our previous observations indicated that $\mathrm{Gd}^{3+}$, a known inorganic inhibitor of mechanogated channels, inhibited the pressure-induced contraction of rat cerebral artery (Masumoto et al., 1997), as was reported by Langton (1993) to occur in isolated single myocytes of the same artery. However, $\mathrm{Gd}^{3+}$ also suppressed high $\mathrm{KCl}$-induced contraction of the artery (Masumoto et al., 1997), indicating a non-specific inhibitory action of $\mathrm{Gd}^{3+}$. Thus, although the presence of mechanogated channel in rat cerebral artery remains to be confirmed, mechanical force could be transferred to integrins and/or mechanogated channels, resulting in the transmembrane ion entry.

It is noteworthy that adhesion plaques are rich in tyrosine kinases such as $s r c$-family and focal adhesion kinase (FAK) (Rohrschneider et al., 1980). In single rabbit ear artery cells, intracellular application of a $s r c$ tyrosine kinase increased $\mathrm{Ca}^{2+}$ channel currents, suggesting that intrinsic $\operatorname{src}$ regulates voltage-dependent $\mathrm{Ca}^{2+}$ channel in vascular smooth muscle cells (Wijetunge \& Hughes, 1996). As nicardipine abolished the 

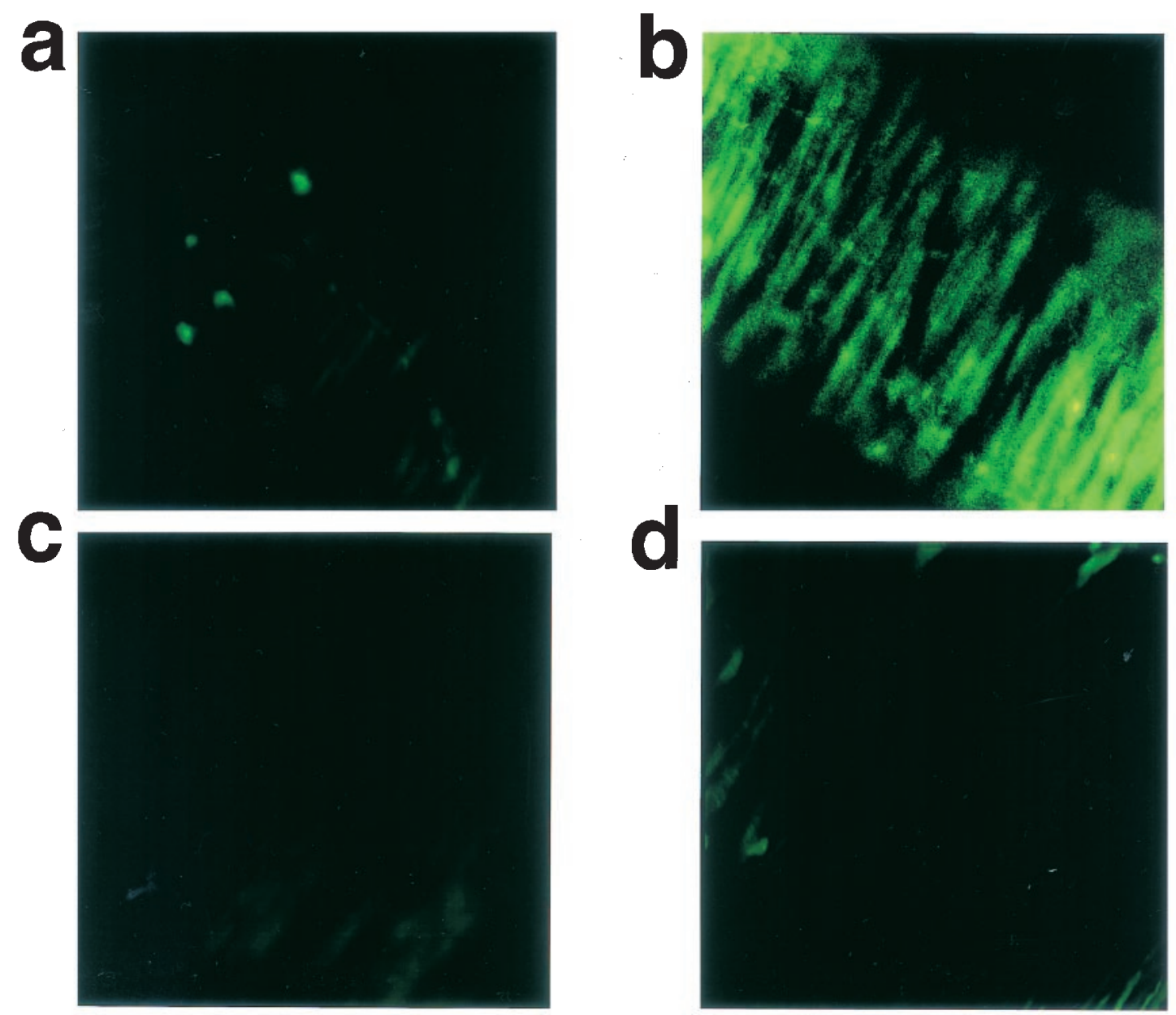

Figure 6 Effects of fasudil and herbimycin A on pressure-induced phosphorylation of tyrosine 419 on pp $60^{\text {src }}$ required for its full catalytic activity. Typical images stained by anti-src $\left[\mathrm{pY}^{418}\right]$ phosphospecific antibody in rat cerebral arteries under control conditions (a) and following exposure to pressurization from 10 to $60 \mathrm{mmHg}$ for $5 \mathrm{~min}$ in the absence (b), or the presence of fasudil $(100 \mu \mathrm{M})(\mathrm{c})$ were shown. Image of an pressurized artery with herbimycin A (100 nM) was also shown (d). Note that the stained individual smooth muscle cells were oriented perpendicular to the longitudinal axis of the artery.

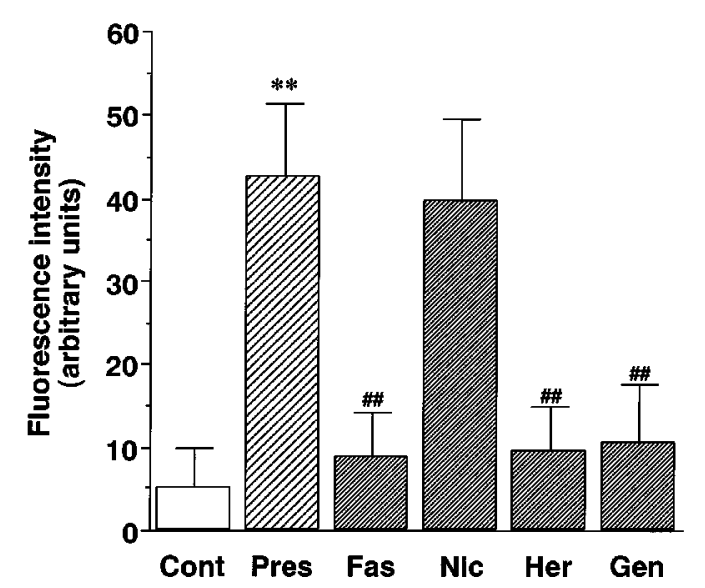

Figure 7 Effects of fasudil, nicardipine, herbimycin A, and genistein on phosphorylation of tyrosine 419 on pp $60^{s r c}$ in rat cerebral artery. Pressurization from 10 to $60 \mathrm{mmHg}$ significantly increased the fluorescence intensity. Note that fasudil (Fas) $(100 \mu \mathrm{M})$, herbimycin A (Her) $(100 \mathrm{~nm})$, and genistein (Gen) $(30 \mu \mathrm{M})$ except nicardipine (Nic) $(100 \mathrm{~nm})$ treatments significantly reduced the fluorescence intensity. Each column represents the mean \pm s.e.mean of five preparations. Cont, control: Pres, pressure. ${ }^{* *}$ indicates $P<0.01$ vs corresponding control values. \#\# indicates $P<0.01$ vs corresponding values stimulated with pressure.

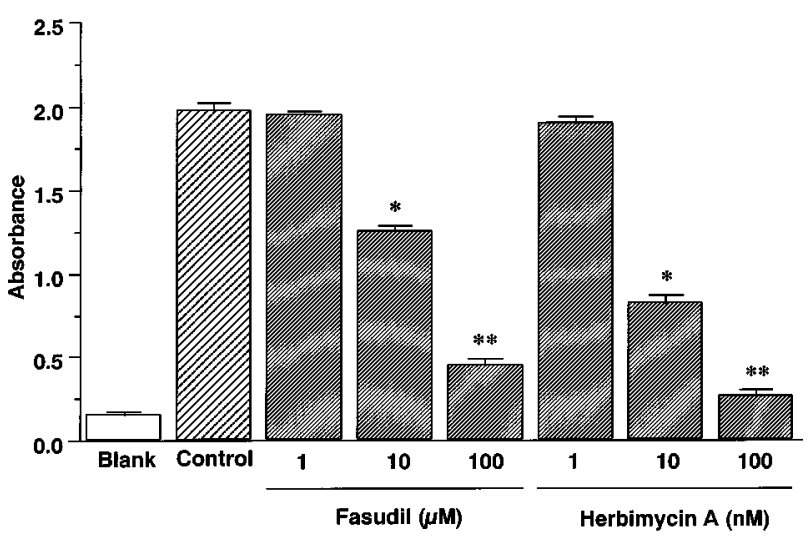

Figure 8 Effects of fasudil and herbimycin A on pp60 $0^{s r c}$ activity in cell free system. Note that fasudil significantly inhibited the pp60 ${ }^{\text {src }}$ activity in a concentration-dependent manner $\left(\mathrm{IC}_{50}\right.$ value $=32.5$ $\pm 2.3 \mu \mathrm{M})$. Herbimycin A also significantly reduced the enzyme activity $\left(\mathrm{IC}_{50}\right.$ value $\left.=8.0 \pm 0.5 \mathrm{nM}\right)$. The absorbance in each well was measured by use of a spectrophotometric plate reader at a wavelength of $450 \mathrm{~nm}$. Each column represents the mean \pm s.e.mean of five determinations. ${ }^{*}$ and $* *$ indicate $P<0.05$ and $P<0.01$, respectively, vs corresponding control values. 
pressure-induced increase in $\left[\mathrm{Ca}^{2+}\right]_{\mathrm{i}}$ and myogenic contraction, but the drug did not suppress not only tyrosine phosphorylation but also pp60 $60^{s r c}$ activity augmented by intraluminal pressurization, we consider that the tyrosine phosphorylation precedes activation of voltage-dependent L-type $\mathrm{Ca}^{2+}$ channels in the myogenic contraction. We recently reported that herbimycin A specifically suppressed the pressure-induced myogenic contraction but did not affect high $\mathrm{KCl}$ - or U46619-induced contractions of the rat cerebral artery (Masumoto et al., 1997), indicating that herbimycin A possesses neither specific inhibitory actions on $\mathrm{Ca}^{2+}$ entry and prostanoid receptors nor non-specific actions.

There are two tyrosine residues that can be phosphorylated on pp60 ${ }^{\text {src }}$ (Piwnica-Worms et al., 1987). In rat, one is tyrosine 530 in the carboxyl-terminal domain, which negatively regulates the kinase activity. Another is tyrosine 419 in the kinase domain, which positively regulates the pp $60^{s r c}$ activity. The sequence containing the tyrosine residue able to increase its kinase activity is conserved in a variety of animal species including rat (Rohrschneider et al., 1979). In the present study, we demonstrated that pressure increased pp60 $60^{s c c}$ activity in the artery, which was assessed by immunocytochemical in situ detection of the phosphorylated tyrosine residue with a phosphospecific antibody. The antibody is against a chemically synthesized phosphopeptide derived from the region of $\mathrm{pp} 60^{\text {src }}$ that contains the tyrosine residue positively regulating its activity. Furthermore, both tyrosine phosphorylation and pp60 $0^{\text {src }}$ activity were suppressed by herbimycin A. We also showed that herbimycin A reduced the the increase in $\left[\mathrm{Ca}^{2+}\right]_{i}$ and myogenic contraction and that orthovanadate potentiated the responses to a pressure stimulus.

Our preliminary experiments also showed that pressureinduced myogenic contraction of rabbit basilar artery and the enhanced tyrosine phosphorylation of various proteins including FAK were effectively inhibited by herbimycin A (Saito et al., 1999). Therefore, according to our studies and those of others, we consider that integrins, herbimycin Asensitive tyrosine kinases including $\mathrm{pp} 60^{s r c}$, and ion channels eliciting membrane depolarization, may interact with one another to assemble focal adhesion plaque, resulting in the regulation of transmembrane $\mathrm{Ca}^{2+}$ entry via voltage-dependent L-type $\mathrm{Ca}^{2+}$ channel in the genesis of myogenic contraction.

Our present study showed that fasudil $(1-100 \mu \mathrm{M})$ effectively inhibited all three kinds of contractions in a similar manner in spite of only partial suppression of the increase in $\left[\mathrm{Ca}^{2+}\right]_{i}$. On the other hand, nicardipine abolished the increment of $\left[\mathrm{Ca}^{2+}\right]_{i}$ and the resultant contractions in response to mechanical or depolarizing stimuli. Asano et al. (1987) indicated that fasudil antagonized competitively $\mathrm{Ca}^{2+}$ influx induced by extracellular high $\mathrm{Ca}^{2+}$ in the rabbit aorta. Therefore, the $\left[\mathrm{Ca}^{2+}\right]_{\mathrm{i}}$ decreased by fasudil, which occurred prior to inhibition of the three types of contractions, could be attributable to its common pharmacological action, i.e., direct blockade of L-type $\mathrm{Ca}^{2+}$ channel. Our present study indicates that herbimycin A-sensitive tyrosine phosphorylation and activation of pp60 $0^{s r c}$, in particular in focal adhesion plaques, seems to be the initial step in the mechanotransduction process of pressure-induced myogenic contraction. In the present study, fasudil effectively suppressed the pressure-induced phosphorylation of tyrosine 419 in the catalytic domain of pp60 $0^{s r c}$. Furthermore, fasudil $(1-100 \mu \mathrm{M})$ directly inhibited the pp60 $0^{\text {src }}$ activity with the $\mathrm{IC}_{50}$ value of about $30 \mu \mathrm{M}$. The $\mathrm{IC}_{50}$ value of fasudil for the pressure-induced contraction was about $5 \mu \mathrm{M}$, which was somehow lower than that for the pp $60^{s r c}$ activity. The difference between the $\mathrm{IC}_{50}$ value of fasudil for the pressure-induced contraction and that for pp $60^{s r c}$ activity is at present unknown. Alternatively, fasudil can disassemble a cascade involved in the mechanotransduction process by inhibition of herbimycin A-sensitive tyrosine phosphorylation via $s r c$-family tyrosine kinase(s), which may also partially contribute to decreasing $\left[\mathrm{Ca}^{2+}\right]_{\mathrm{i}}$ in the case of pressure-induced contraction.

Our present experiments showed that high $\mathrm{KCl}$-stimulation did not clicit tyrosine phosphorylation in the rat cerebral artery. In addition, herbimycin A, genistein, and orthovanadate had no apparent effect on high $\mathrm{KCl}$-induced increase in $\left[\mathrm{Ca}^{2+}\right]_{\mathrm{i}}$ and contraction. These findings suggest that the inhibitory mechanism of fasudil of the contractile response to a depolarizing stimulus is not due to its elimination of tyrosine phosphorylation but due to other actions, including its direct blockade of the transmembrane $\mathrm{Ca}^{2+}$ entry via voltagedependent L-type $\mathrm{Ca}^{2+}$ channels.

Recently, it has been reported that protein tyrosine phosphorylation could be also involved in receptor-mediated increase in $\left[\mathrm{Ca}^{2+}\right]_{\mathrm{i}}$ and subsequent contractions of arterial smooth muscle. In isolated smooth muscle cells from porcine coronary arteries, genistein effectively inhibited the initial transient $\left[\mathrm{Ca}^{2+}\right]_{\mathrm{i}}$ and sustained $\left[\mathrm{Ca}^{2+}\right]_{\mathrm{i}}$ responses to endothelin1 , suggesting the involvement of tyrosine kinase in the regulatory mechanism for the peptide-induced $\left[\mathrm{Ca}^{2+}\right]_{\mathrm{i}}$ responses in the coronary artery (Liu et al., 1996). Endothelin-1 $(1-100 \mathrm{nM})$ produced rapid $(20 \mathrm{~s})$ and sustained (up to $20 \mathrm{~min}$ ) increases in protein tyrosine phosphorylation levels in four main clusters of proteins in rat mesenteric artery, which occurred even in the $\mathrm{Ca}^{2+}$-free medium (Ohanian et al., 1997). Here, we demonstrated that U46619 augmented not only $\left[\mathrm{Ca}^{2+}\right]_{\mathrm{i}}$ but also tyrosine phosphorylation, as well as the subsequent contraction and that these augmentations were effectively inhibited by genistein but not herbimycin A or daidzein. In addition, orthovanadate augmented U46619induced increase in $\left[\mathrm{Ca}^{2+}\right]_{\mathrm{i}}$ and contractile activity. Although genistein has been recently reported to possess non-specific effects such as a direct action on $\mathrm{Cl}^{-}$channel proteins (Hwang et al., 1997; Zhou et al., 1998), our present study suggests that tyrosine phosphorylation, sensitive to genistein but not to herbimycin $\mathrm{A}$, is involved in the mechanism governing the contractile processes in the U46619-induced contraction of rat cerebral artery. It seems possible that a common signalling pathway involving cytosolic tyrosine kinase(s) sensitive to genistein may play a role in the mechanism of contractions produced by pressure and U46619 (Masumoto et al., 1997).

Although fasudil only partially suppressed the increase in $\left[\mathrm{Ca}^{2+}\right]_{\mathrm{i}}$, the drug totally attenuated the three different kinds of contractile responses. It is generally considered that the $\mathrm{Ca}^{2+}$. dependent phosphorylation of myosin light chain (MLC) is one of the most important mechanisms involved in the contraction of smooth muscle. We previously reported that ML-9 [1-(5-chloronaphthalene-1-sulphonyl)-1H-hexahydro1,4-diazepine hydrochloride], a MLC kinase inhibitor, almost completely depressed the mechanical reactivity elicited by quick stretch, but only slightly attenuated the $\left[\mathrm{Ca}^{2+}\right]_{i}$ (Nakayama \& Tanaka, 1988). Fasudil possesses an inhibitory effect on $\mathrm{Ca}^{2+} /$ calmodulin-dependent MLC kinase (Asano et al., 1989; Katsumata et al., 1997; Seto et al., 1991, 1995; Uehata et al., 1997), which may contribute to the attenuation of the three different kinds of contractile responses. We previously reported that $\mathrm{U} 46619$ increased not only the influx of $\mathrm{Ca}^{2+}$ but also the release of $\mathrm{Ca}^{2+}$ from intracellular storage sites, as well as heightened the $\mathrm{Ca}^{2+}$ sensitivity of the contractile elements in the canine basilar artery (Tanaka et al., 1995). Since fasudil also suppresses protein kinases 
involved in $\mathrm{Ca}^{2+}$ sensitization, such as protein kinase $\mathrm{C}$ (Asano et al., 1989; Uehata et al., 1997) and Rho-associated kinase (Uehata et al., 1997), the drug effectively inhibited the U46619-induced contraction.

As to pathophysiological interventions, Katsumata et al. (1997) reported an enhancement of MLC phosphorylation as a central mechanism for coronary artery spasm in a swine model with interleukin $1 \beta$. Fasudil dose-dependently inhibited the serotonin-induced coronary hyperconstriction due to its suppression of MLC phosphorylation in this model. Cerebral vasospasm, a persistent narrowing of major cerebral arteries, is a major cause of mortality and morbidity following $\mathrm{SAH}$. The components of crythrocyte lysate, such as oxyhaemoglobin and other molecules, have been proposed as causative agents. Recently, it has been reported that haemolysate induced tyrosine phosphorylation in endothelial cells of bovine cerebral artery (Marton et al., 1996) and in smooth muscle cells of rat cerebral artery (Iwabuchi et al., 1999). Furthermore, Kim et al. (1998) reported that erythrocyte lysate-induced contraction was inhibited by genistein in the rabbit basilar artery.
Therefore, it is likely that tyrosine phosphorylation may play an important role in the genesis of cerebral vasospasm after SAH and that tyrosine kinase inhibitors may be a good alternative in the management of this pathological condition. Our unpublished experiments indicated that fasudil inhibited effectively the potentiation of the pressure-induced contraction by hemolysate. Furthermore, the present study demonstrates that fasudil effectively inhibited the pressure-induced myogenic contraction, total tyrosine phosphorylation level, and phosphorylation of tyrosine 419 on pp60 ${ }^{s r c}$ required for its full catalytic activity in the rat cerebral artery as well as pp60 $6{ }^{s r c}$ activity in the cell free system. The wide spectrum of inhibitory actions of fasudil may contribute to its effective attenuation of the pressure-induced contraction.

The present study was supported in part by grants-in-aid for scientific research (Nos. 02304033, 02671005, 04671360, 07672370, 08557139 and 10672046) from the Ministry of Education, Science, and Culture of Japan, and by grants from the Shizuoka Research and Development Foundation.

\section{References}

ASANO, T., IKEGAKI, I., SATOH, S., SUZUKI, Y., SHIBUYA, M., TAKAYASU, M. \& HIDAKA, H. (1987). Mechanism of action of a novel antivasospasm drug, HA1077. J. Pharmacol. Exp. Ther. 241, $1033-1040$

ASANO, T., SUZUKI, T., TSUCHIYA, M., SATOH, S., IKEGAKI, I., SHIBUYA, M., SUZUKI, Y. \& HIDAKA, H. (1989). Vasodilator actions of HA 1077 in vitro and in vivo putatively mediated by the inhibition of protein kinase. Br. J. Pharmacol., 98, 1091-1100.

D'ANGELO, G., DAVIS, M.J. \& MEININGER, G.A. (1997a). Calcium and mechanotransduction of the myogenic response. Am. J. Physiol., 273, H175-H182.

D'ANGElo, G., MOGFORD, J.E., DAVIS, G.E., DAVIS, M.J. \& MEININGER, G.A. (1997b). Integrin-mediated reduction in vascular smooth muscle $\left[\mathrm{Ca}^{2+}\right]_{\mathrm{i}}$ induced by RGD-containing peptide. Am. J. Physiol., 272, H2065-H2070.

HIMPENS, B., SMEDT, H.D., DROOGMANS, G. \& CASTEELS, R. (1992). Differences in regulation between nuclear and cytoplasmic $\mathrm{Ca}^{2+}$ in cultured smooth muscle cells. Am. J. Physiol., 263, C95-C105.

HWANG, T.-C., WANG, F., YANG, I.C.-H. \& REENSTRA, W.W. (1997). Genistein potentiates wild-type and $\triangle$ F508-CFTR channel activity. Am. J. Physiol., 273, C988-C998.

INGBER, D. (1991). Integrins as mechanochemical transducers. Curr. Opin. Cell. Biol., 3, $841-848$.

ISHII, K., CHANG, B., KERWIN, J.F., HUANG, Z.J. JR. \& MURAD, F. (1990). $N^{(1)}$-Nitro-L-arginine: a potent inhibitor of endotheliumderived relaxing factor formation. Eur. J. Pharmacol., 176, $219-$ 223.

IWABUCHI, S., MARTON, L.S. \& ZHANG, J.H. (1999). Role of protein tyrosine phosphorylation in crythrocyte lysate-induced intracellular free calcium concentration elevation in cerebral smoothmuscle cells. J. Neurosurg., 90, 743-751.

KATSUMATA, N., SHIMOKAWA, H., SETO, M., KOZAI, T., YAMAWAKI, T., KUWATA, K., EGASHIRA, K., IKEGAKI, I., ASANO, T., SASAKI, Y. \& TAKESHITA, A. (1997). Enhanced myosin light chain phosphorylations as a central mechanism for coronary artery spasm in a swine model with interleukin-1 $\beta$. Circulation, 96, $4357-4363$.

KIM, C.J., KIM, K.W., PARK, J.W., LEE, J.C. \& ZHANG, J.H. (1998). Role of tyrosine kinase in erythrocyte lysate-induced contraction in rabbit cerebral arteries. J. Neurosurg., 89, 289-296.

LANGTON, P.D. (1993). Calcium channel currents recorded from isolated myocytes of rat basilar artery are stretch sensitive. $J$. Physiol., 471, $1-11$.

LEHOUX, S. \& TEDGUI, A. (1998). Signal transduction of mechanical stress in the vascular wall. Hypertension, 23, $338-345$.

LIU, C.Y.\& STUREK, M. (1996). Attenuation of end othelin-1-induced calcium response by tyrosine kinase inhibitors in vascular smooth muscle cells. Am. J. Physiol., 270, C1825-C1833.

MARTON, L.S., WEIR, B.K.A. \& ZHANG, H. (1996). Tyrosine phosphorylation and $\left[\mathrm{Ca}^{2+}\right]_{i}$ elevation induced by hemolysate in bovine endothelial cells: Implications for cerebral vasospasm. Neurol. Res., 18, 349-353.

MASUMOTO, N., NAKAYAMA, K., OYABE, A., UCHINO, M., ISHII, K., OBARA, K. \& TANABE, Y. (1997). Specific attenuation of the pressure-induced contraction of rat cerebral artery by herbimycin A. Eur. J. Pharmacol., 330, 55-63.

MEININGER, G.A., ZAWIEJA, D.C., FALCONE, J.C., HILL, M.A. \& DAVEY, J.P. (1991). Calcium measurement in isolated arterioles during myogenic and agonist stimulation. Am. J. Physiol., 261, $\mathrm{H} 950$ - H959.

MOGFORD, J.E., DAVIS, G.E., PLATTS, S.H. \& MEININGER, G.A. (1996). Vascular smooth muscle $\alpha_{\mathrm{v}} \beta_{3}$ integrin mediates arteriolar vasodilation in response to RGD peptides. Circ. Res., 79, $821-$ 826.

MULLER, J.M., CHILIAN, W.M. \& DAVIS, M.J. (1997). Integrin signaling transduces shear stress-dependent vasodilation of coronary arterioles. Circ. Res., 80, 320-326.

MULLER, J.M., DAVIS, M.J. \& CHILIAN, W.M. (1996). Coronary arteriolar flow-induced vasodilation signals through tyrosine kinase. Am. J. Physiol., 270, H1878-H1884.

NAKAYAMA, K. (1982). Calcium-dependent contractile activation of cerebral artery produced by quick stretch. Am. J. Physiol., 242, H760 - H768.

NAKAYAMA, K. (1988). Active and passive mechanical properties of ring and spatial segments of isolated dog basilar artery assessed by electrical and pharmacological stimulations. Blood Vessels, 25, $285-298$.

NAKAYAMA, K. \& TANAKA, Y. (1988). Calcium transients and stretch-induced myogenic tone in vascular tissue. In: Resistance Arteries. ed. Halpern, W. et al. pp. 212-218. New York: Periatology Press.

NAKAYAMA, K., TANAKA, Y. \& FUJISHIMA, K. (1989). Potentiation of stretch-induced myogenic tone of dog cerebral artery by hemolysate and inhibitory action of calcium antagonists. Eur. J. Pharmacol., 169, $33-42$.

OHANIAN, J., OHANIAN, V., SHAW, L., BRUCE, C. \& HEAGERTY, A.M. (1997). Involvement of tyrosine phosphorylation in endothelin-1-induced calcium-sensitization in rat small mesenteric arteries. Br. J. Pharmacol., 120, 653-661.

OSOL, G. (1995). Mechanotransduction by vascular smooth muscle. J. Vasc. Res., 32, 275-292.

PIWNICA-WORMS, H., SAUNDERS, K.B., ROBERTS, T.M., SMITH, A.E. \& CHENG, S.H. (1987). Tyrosine phosphorylation regulates the biochemical and biological properties of pp60 $60^{c-s r}$. Cell, 49, $75-82$. 
ROHRSCHNEIDER, L.R. (1980). Adhesion plaques of Rous sarcoma virus-transformed cells contain the $\operatorname{src}$ gene product. Proc. Natl. Acad. Sci. U.S.A., 77, 3514-3518.

ROHRSCHNEIDER, L.R., EISENMAN, R.N. \& LEITCH, C.R. (1979). Identification of a Rous sarcoma virus transformation-related protein in normal avian and mammalian cells. Proc. Natl. Acad. Sci. U.S.A., 76, $4479-4483$.

RUOSLAHTI, E. \& PIERSBACHER, M.D. (1986). Arg-Gly-Asp: a versatile cell recognition signal. Cell, 44, 517-518.

RUOSLAHTI, E. \& PIERSBACHER, M.D. (1987). New perspectives in cell adhesion: RGD and integrins. Science, 238, 491-497.

SAITO, M., TANABE, Y., MASUMOTO, N., ISHIKAWA, T., OBARA, K., HORIE, N., TAKEISHI, K. \& NAKAYAMA, K. (1999). Differential augmentation by mechanical stretch of protein tyrosine phosphorylation in medial smooth muscle and endothelial cells isolated from rabbit pulmonary arteries. Japan. J. Pharmacol., 79 (Suppl. 1): 85.

SCHRAAG, B., STAAL, G.E.J., ADRIAANSEN-SLOT, S.S., SALDEN, M \& RIJKSEN, G. (1993). Standardization of an enzyme-linked immunosorbent assay for the determination of protein tyrosine kinase activity. Anal. Biochem., 211, 233-239.

SCHWARTZ, M.A., BROWN, E.J. \& FAZELI, B. (1993). A 50-kDa integrin-associated protein is required for integrin-regulated calcium entry in endothelial cells. J. Biol. Chem., 268, 1993119934.

SETO, M., SASAKI, Y., SASAKI, Y. \& HIDAKA, H. (1991). Effects of HA1077, a protein kinase inhibitor, on myosin phosphorylation and tension in smooth muscle. Eur. J. Pharmacol., 195, 267-272.

SETO, M., SHINDO, K., ITO, K. \& SASAKI, Y. (1995). Selective inhibition of phosphorylation and tension of hyperplastic arteries by the kinase inhibitor HA1077. Eur. J. Pharmacol., 276, $27-33$
SHIROTANI, M., YUi, Y., HATTORI, R. \& KAWAI, C. (1991). A new type of vasodilator, HA1077, an isoquinoline derivative, inhibits proliferation of bovine vascular smooth muscle cells in culture. $J$. Phamacol. Exp. Ther., 259, $738-744$.

TAKAYASU, M., SUZUKI, Y., SHIBUYA, M., ASANO, T., KANAMORI, M., OKADA, T., KAGEYAMA, N. \& HIDAKA, H. (1986). The effects of HA compound calcium antagonists on delayed cerebral vasospasm in dogs. J. Neurosurg., 65, 80-85.

TAKIZAWA, S., HORI, M., OZAKI, H. \& KARAKI, H. (1993). Effects of isoquinoline derivatives, HA1077 and $\mathrm{H}-7$, on cytosolic $\mathrm{Ca}^{2+}$ level and contraction in vascular smooth muscle. Eur. J. Pharmacol., 250, $431-437$.

TANAKA, Y., NAKAZAWA, T., ISHIRO, H., SAITO, M., UNEYAMA, H., IWATA, S., ISHII, K. \& NAKAYAMA, K. (1995). $\mathrm{Ca}^{2+}$ handling mechanisms underlying neuropeptide $\mathrm{Y}$-induced contraction in canine basilar artery. Eur. J. Pharmacol., 289, 59-66.

UEHATA, M., ISHIZAKI, T., SATOH, H., ONO, T., KAWAHARA, T., MORISHITA, T., TAMAKAWA, H., YAMAGAMI, K., INUI, J., MAEKAWA, M. \& NARUMIYA, S. (1997). Calcium sensitization of smooth muscle mediated by a Rho-associated protein kinase in hypertension. Nature, 389, $990-994$.

WIJETUNGE, S. \& HUGHES, A.D. (1996). Activation of endogenous $\mathrm{c}-\mathrm{Src}$ or a related tyrosine kinase by intracellular (pY)EEI peptide increases voltage-operated calcium channel currents in rabbit ear artery cells. FEBS Lett., 399, 63-66.

ZHOU, S.-S., HAZAMA, A. \& OKADA, Y. (1998). Tyrosine kinaseindependent extracellular action of genistein on the CFTR $\mathrm{Cl}^{-}$ channel in guinea pig ventricular myocytes and CFTRtransfected mouse fibroblasts. Japan. J. Physiol., 48, 389-396.

(Received December 8, 1999 Accepted February 22, 2000) 